\title{
MODIFICATION OF THE OESTROUS CYCLE OF THE UNDERFED RAT ASSOCIATED WITH THE TIME OF FEEDING
}

\author{
K. J. COOPER AND N. B. HAYNES \\ University of Nottingham, School of Agriculture, Sutton Bonington, \\ Loughborough, Leicestershire
}

(Received 17th March 1969)

\begin{abstract}
Summary. The effect of dietary restriction on the oestrous cycle of rats was modified by the time of feeding. There was a significant decrease in the cyclic activity in a group of rats fed at 17.00 hours when compared with a group fed at 12.00 hours $(P<0.01)$.
\end{abstract}

The establishment of lengthened oestrous cycles and the subsequent cessation of cyclic activity in rats by dietary restriction has been demonstrated many times (Mulinos \& Pomerantz, 1940; Rinaldini, 1949). Oestrous activity may be resumed in a group of such non-cycling rats when they are subjected to the stimulus of constant illumination (Piacsek \& Meites, 1965) and the long irregular cycles of underfed rats become more normal in the presence of the male (Cooper \& Haynes, 1967). In the underfed gilt, a period of re-feeding just before ovulation appears to increase the ovulation rate (Lodge \& Hardy, 1968) and, conversely, starvation of mice just before oestrus prevents ovulation (McClure, 1967). This has led to the suggestion that a nutrition-induced pituitary block of ovulatory gonadotrophin secretion may be removed by external factors such as light, the presence of the male or a short period of re-feeding. The fact that ovulation may be influenced by altering the feeding régime during a very short interval before the event provided the basis for experiments described here. Work is in progress on the effect of undernutrition on cyclic behaviour in the rat and it seemed possible that the results might be influenced by the time at which the daily food quota was given, particularly during the period just before ovulation. LH in rat plasma rises to a peak late in pro-oestrus (Ramirez \& McCann, 1964) and the ovulatory surge of gonadotrophins is released between 14.00 and 16.00 hours in rats subjected to illumination from 05.00 to 19.00 hours, the process of ovulation occurring some $10 \mathrm{hr}$ later (Everett, 1948; Everett, Sawyer \& Markee, 1949; Everett \& Sawyer, 1953; Barraclough \& Sawyer, 1955). The rats used here were on an 08.00- to 20.00 -hours light régime and ovulated in the early morning. It was assumed, therefore, that the period of heightened gonadotrophin release in these rats would also occur in mid-afternoon. An investigation into the effect of different times of feeding, i.e. before and after the time of expected increase in gonadotrophin release was carried out. Eighty female Wistar strain rats, 24 to 26 weeks 
old, showing normal cycles of 4 to 5 days as determined by vaginal smears, were allocated randomly to three groups and individually caged under the lighting régime already described. Twenty were fed without restriction and two groups of thirty were fed $70 \%$ of the unrestricted intake; a level of feeding and diet known to cause an increasing proportion of rats to show lengthened cycles with increasing time of restriction (Cooper \& Haynes, 1967). One group was given the daily feed at noon and the other at 17.00 hours. The time to consume a daily feed varied from 1 to $3 \mathrm{hr}$. Vaginal smears were examined daily. Cyclic activity was expressed as the number of rats which showed an oestrus-type smear during a period of 5 days divided by the total number of

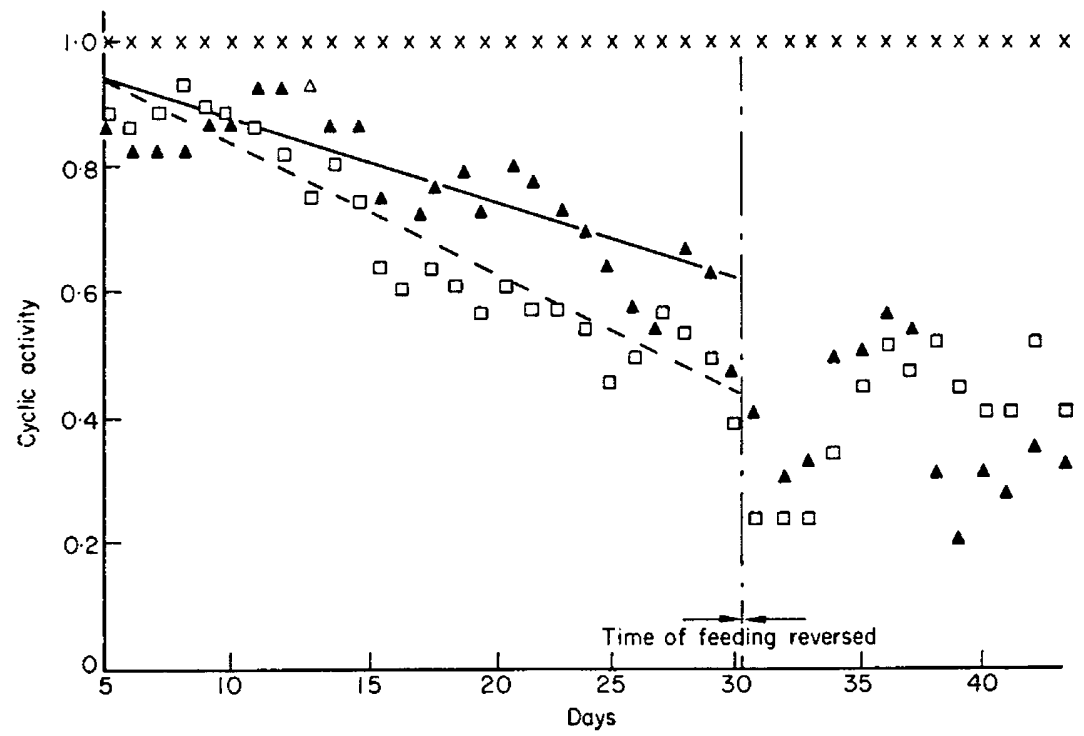

TEXT-FIG. 1. Cyclic activity in three groups of rats: (a) fed without restriction $\times$; (b) fed $70 \%$ of the unrestricted intake at noon to 30 days then 17.00 hours: $\Delta$; regression (-) $y=0.95-0.14 x, R=-0.836$; (c) fed $70 \%$ of the unrestricted intake at 17.00 hours to 30 days then noon: $\square$; regression $(----) y=0.95-0.02 x, R=-0.953$. Cyclic activity is expressed as the number of rats in a group which showed an oestrous smear during a period of 5 days divided by the total number of rats in the group.

rats in the group. During the early stages of underfeeding, some rats showed two oestrous smears during a 5-day period. One value was ignored and the rats were considered as single cycling animals. The results were calculated daily, i.e. over Days 1 to 5,2 to 6,3 to 7 to Day 30 when the time of feeding for the two underfed groups was reversed and the experiment continued for 15 days. Cyclic activity is shown in Text-fig. 1. The number of rats showing oestrus during a 5-day period remained constant in the unrestricted group. There was a gradual decrease in the underfed groups with a divergence becoming apparent after about 10 days of underfeeding. Regression analysis demonstrated that cyclic activity was significantly greater $(P<0.01)$ in the group fed at noon to Day 30 , compared with the group fed at 17.00 hours. Reversal of the feeding caused fluctuation but eventually reversed the incidence of oestrus in the two groups. 
Underfeeding at the level used did not affect all rats equally. In the noon group, ten animals continued to show 4- to 5-day cycles, ten animals had irregular but lengthened cycles of 5 to 9 days and the remaining ten ceased to show cyclic activity. In the 17.00 hours group, the corresponding numbers were four, thirteen and thirteen. The figures suggest that the rats sensitive to dietary restriction are also sensitive to small environmental changes. In these animals, a nutrition-induced pituitary block may at least be partly removed by temporary alleviation of an underfeeding syndrome just before a normal ovulatory gonadotrophin surge. This may stimulate increased oestrogen secretion and result in an oestrous vaginal smear. Whether this is brought about by removal of a hunger stress, or a change in the level of an essential nutrient, is not clear from this work, but since similar effects are obtained by the introduction of a male, the latter cause seems unlikely. Further, it has been suggested that the rat on unrestricted food may have a natural feeding rhythm. The results could then be a consequence of imposing a degree of interference upon this rhythm by giving a single feed, the degree of interference and resultant stress being greater in the 17.00-hours than in the noon group. Experiments are planned to investigate this possibility. Nevertheless, whatever the mechanism, in studies involving the effects of nutrition on cyclic behaviour, the time of feeding is important and must be controlled within narrow limits.

The authors are grateful to the Pig Industry Development Authority for support.

\section{REFERENCES}

BarRaclough, C. A. \& SAWYer, C. H. (1955) Inhibition of the release of pituitary ovulatory hormone in the rat by morphine. Endocrinology, 57, 329.

CoOper, K. J. \& HAynes, N. B. (1967) Modification of the oestrous cycle of the underfed rat associated with the presence of the male. F. Reprod. Fert. 14, 317.

Everetr, J. W. (1948) Progesterone and oestrogen in the experimental control of ovulation time and other features of the oestrous cycle in the rat. Endocrinology, 43, 389.

EVERETT, J. W. \& SAWYER, C. H. (1953) Estimated duration of the spontaneous activation which causes release of ovulating hormone from the rat hypophysis. Endocrinology, 52, 83.

EveretT, J. W., Sawyer, C. H. \& MARKeE, J. E. (1949) A neurogenic timing factor in control of the ovulatory discharge of luteinising hormone in the cyclic rat. Endocrinology, 44, 234.

Lodge, G. A. \& HARDY, B. (1968) The influence of nutrition during oestrus on ovulation rate in the sow. 7. Reprod. Fert. 15, 329.

MCCluRe, T. J. (1967) Infertility in mice caused by fasting at about the time of mating. F. Reprod. Fert. 13, 387.

Mutinos, M. G. \& Pomerantz, L. (1940) Pseudohypophysectomy-a condition resembling hypophysectomy produced by malnutrition. $\mathcal{F}$. Nutr. 19, 493.

Piacsek, B. E. \& Meites, J. (1965) Reinitiation of gonadotrophin release in starved rats by constant light or adrenaline. (Abstract). Program of the 47th Meeting of the Endocrine Society, p. 117.

RAMIREZ, V. D. \& MaCANN, S. M. (1964) Fluctuations in plasma luteinising hormone concentrations during the oestrous cycle of the rat. Endocrinology, 74, 814.

Rinaldini, L. M. (1949) Effect of chronic inanition on the gonadotrophic content of the pituitary gland. F. Endocr. 6, 54. 